\title{
Clinical features and symptom recovery on a gluten-free diet in Canadian adults with celiac disease
}

\author{
Olga Pulido MD MSc ${ }^{1,2}$, Marion Zarkadas $\mathrm{MSc}^{3}$, Sheila Dubois $\mathrm{PhD}^{1}$, Krista Maclsaac MSc ${ }^{4}$, Isabelle Cantin MSc ${ }^{1}$, \\ Sébastien La Vieille MD MSc ${ }^{1}$, Samuel Godefroy PhD ${ }^{1}$, Mohsin Rashid MBBS MEd FRCPC ${ }^{3,5}$
}

O Pulido, M Zarkadas, S Dubois, et al. Clinical features and symptom recovery on a gluten-free diet in Canadian adults with celiac disease. Can J Gastroenterol 2013;27(8):449-453.

BACKGROUND: Celiac disease can present with mild or nongastrointestinal symptoms, and may escape timely recognition. The treatment of celiac disease involves a gluten-free diet, which is complex and challenging.

OBJECTIVE: To evaluate clinical features and symptom recovery on a gluten-free diet in a Canadian adult celiac population.

METHODS: All adult members $(n=10,693)$ of the two national celiac support organizations, the Canadian Celiac Association and Fondation québécoise de la maladie coeliaque, were surveyed using a questionnaire. RESULTS: A total of 5912 individuals ( $\geq 18$ years of age) with biopsyconfirmed celiac disease and/or dermatitis herpetiformis completed the survey. The female to male ratio was $3: 1$, and mean $( \pm S D)$ age at diagnosis was $45.2 \pm 16.4$ years. Mean time to diagnosis after onset of symptoms was $12.0 \pm 14.4$ years. Abdominal pain and bloating $(84.9 \%)$, extreme weakness/tiredness (74.2\%), diarrhea (71.7\%) and anemia $(67.8 \%)$ were the most commonly reported symptoms at the time of diagnosis. Many respondents continued to experience symptoms after being on a gluten-free diet for $>5$ years. Sex differences were reported in clinical features before diagnosis, recovery after being on gluten-free diet and perceived quality of life, with women experiencing more difficulties than men.

CONCLUSIONS: Delays in diagnosis of celiac disease in Canada remain unacceptably long despite wider availability of serological screening tests. Many patients report continuing symptoms despite adhering to a gluten-free diet for $>5$ years, with women experiencing more symptoms and a lower recovery rate than men. Awareness of celiac disease needs improvement, and follow-up with a physician and a dietitian is essential for all patients with celiac disease.

Key Words: Celiac disease; Cross-sectional study; Gluten-free diet; Recovery; Symptoms

Celiac disease (CD) is a chronic, small intestinal immune-mediated enteropathy caused by exposure to dietary gluten (a protein in wheat, rye and barley) in genetically susceptible individuals. It is a common disorder estimated to affect approximately $1 \%$ of the population. Although the true prevalence of CD in Canada is not known, a large population-based study from the United States found the prevalence to be one in 133 individuals (1). Based on clinical features and disease pathogenesis, several gluten-related disorders are now recognized including $\mathrm{CD}$, dermatitis herpetiformis, gluten ataxia, wheat allergy and nonceliac gluten sensitivity $(2,3)$.

Excellent serological tests, such as antitissue transglutaminase (TTG) antibody (immunoglobulin [Ig] A anti-TTG) and antiendomysial antibody (IgA EMA) are now available to screen for CD. These tests have a sensitivity and specificity $>90 \%(4,5)$, and are of great use in screening minimally symptomatic or high-risk patients. Because of

\section{Les caractéristiques cliniques et la disparition des symptômes chez des adultes canadiens ayant une maladie cœliaque qui suivent un régime sans gluten}

\begin{abstract}
HISTORIQUE : La maladie cœliaque, qui peut s'accompagner de symptômes gastro-intestinaux légers ou d'autres symptômes, risque de ne pas être dépistée rapidement. Pour la traiter, il faut adopter un régime sans gluten, difficile et complexe.

OBJECTIF : Évaluer les caractéristiques cliniques et la disparition des symptômes dans une population canadienne d'adultes ayant la maladie cœliaque qui suivent un régime sans gluten.

MÉTHODOLOGIE : À l'aide d'un questionnaire, les chercheurs ont sondé tous les membres adultes $(n=10$ 693) des deux organismes nationaux de soutien de la maladie cœeliaque, l'Association canadienne de la maladie cœliaque et la Fondation québécoise de la maladie cœliaque.

RÉSULTATS : Au total, 5912 personnes (de 18 ans ou plus) ayant une maladie cœliaque confirmée par biopsie ou une dermatite herpétiforme ont rempli le sondage. Le ratio entre les femmes et les hommes était de 3:1, et l'âge moyen ( $\pm E$ Ė) au diagnostic, de 45,2 $\pm 16,4$ ans. Le délai moyen jusqu'au diagnostic après l'apparition des symptômes était de $12,0 \pm 14,4$ ans. Les douleurs abdominales et les gonflements $(84,9 \%)$, une faiblesse ou une fatigue extrême (74,2 \%), la diarrhée (71,7 \%) et l'anémie (67,8\%) étaient les symptômes les plus déclarés au moment du diagnostic. De nombreux répondants continuaient de ressentir des symptômes au bout de plus de cinq ans de régime sans gluten. On remarquait des différences selon le sexe dans les caractéristiques cliniques avant le diagnostic, le rétablissement après le début du régime sans gluten et la qualité de vie, les femmes éprouvant plus de difficultés que les hommes.

CONCLUSIONS : Le délai de diagnostic de la maladie cœliaque demeure inacceptable, malgré la plus grande accessibilité des tests de dépistage sérologique. De nombreux patients déclarent continuer de ressentir des symptômes même s'ils suivent un régime sans gluten depuis plus de cinq ans, les femmes éprouvant plus de symptômes et un taux de rétablissement plus faible que les hommes. Il faut accroître les connaissances sur la maladie cœliaque, et un suivi avec un médecin et un diététiste est essentiel pour tous les patients atteints.
\end{abstract}

the wider availability of these tests in clinical practice, increasing numbers of individuals with this disorder are being identified (6). The diagnosis of CD must be confirmed with small intestinal biopsies.

The only effective treatment currently available for CD is a strict, lifelong gluten-free (GF) diet $(7,8)$. This involves elimination of all foods, beverages and medications made with wheat, rye or barley, and their crossbred grains. The GF diet is complex, challenging and can be socially restrictive (9-13). Avoiding cross contamination can be difficult because wheat is ubiquitous in the Western diet. While symptoms and intestinal injury improve on a GF diet, many individuals do not fully recover $(13,14)$.

The clinical spectrum of $\mathrm{CD}$ is wide, including classical, nonclassical, subclinical and potential forms $(3,4)$. The symptoms of CD are also highly variable both in character and severity. These can develop at any age when gluten is present in the diet, and can be both

\footnotetext{
${ }^{1}$ Food Directorate, Health Canada; ${ }^{2}$ Faculty of Medicine, University of Ottawa, Ottawa, Ontario; ${ }^{3}$ Canadian Celiac Association, Professional Advisory Board; ${ }^{4}$ Canadian Celiac Association, Mississauga, Ontario; ${ }^{5}$ Faculty of Medicine, Dalhousie University, Halifax, Nova Scotia

Correspondence: Dr Mohsin Rashid, Division of Gastroenterology $\mathcal{E}$ Nutrition, Department of Paediatrics, Faculty of Medicine, Dalhousie University,

IWK Health Centre, 5850 University Avenue, Halifax, Nova Scotia B3K 6R8. Telephone 902-470-8746, fax 902-470-7249,

e-mailmohsin.rashid@iwk.nshealth.ca

Received for publication April 7, 2013. Accepted May 12, 2013
} 
intestinal and extraintestinal in nature $(15,16)$. In many cases of CD, the classical symptoms of malabsorption, such as diarrhea and weight loss, tend to manifest later in the disease process. In adults, extraintestinal clinical presentations include anemia, bone pain and neurological disturbances such as ataxia and peripheral neuropathy $(17,18)$. Such variability of presentation can frequently contribute to misdiagnoses $(10,19,20)$.

Other autoimmune conditions, such as type 1 diabetes and hypothyroidism, occur more frequently in patients with CD (21,22). Poorly treated CD can result in complications including osteoporosis, infertility and lymphoproliferative disorders (23-25). CD is associated with a higher overall mortality rate (24-26).

The aim of the present study was to characterize the clinical features, time to diagnosis and symptom recovery after treatment in adults with CD and dermatitis herpetiformis.

\section{METHODS}

All members of the Canadian Celiac Association (CCA) and the Fondation québécoise de la maladie coeliaque (FQMC) were surveyed using a questionnaire. These are Canada's two major celiac support organizations with wide representation from all regions, with FQMC members being primarily French speaking. The questionnaire contained items regarding demographic information, diagnosis, symptoms and their recovery on a GF diet. The study had two components: investigating clinical features of $\mathrm{CD}$, which is presented in the current article; and evaluating the emotional impact and difficulties experienced with the GF diet. Results of the latter component are reported elsewhere (27).

The survey questionnaire was developed in English and translated into French. Language equivalence was assessed by bilingual subject matter and survey-methodology experts. It was pretested by CCA and FQMC members. The questionnaire was mailed in December 2008. Only one mailing was performed.

Individuals $\geq 18$ years of age were eligible to participate in the survey. If there was more than one eligible family member in a household, they were asked to request an additional questionnaire(s). A total of 10,693 households with current memberships in the CCA $(n=7872$ English) and FQMC (n=2821 French) were surveyed. Complete anonymity of the respondents was maintained. On return, each questionnaire was assigned a unique identifying code. Questionnaire completion and return was regarded as consent.

Only data from respondents $(\mathrm{n}=5912)$ with biopsy-confirmed CD and dermatitis herpetiformis were studied. The data were entered and analyzed using SPSS version 18 (IBM Corporation, USA). Because not all respondents answered all of the questions, and there was no treatment of missing values, the number of respondents to each question was variable. Continuous data are summarized as mean \pm SD. Discrete data are presented as frequency (percentage). ANOVA and Pearson $\chi^{2}$ tests were used to test for significance between groups. All statistical tests were two-sided. Tests were considered to be statistically significant based on an alpha value of 0.01 .

The study was approved by the Ethics Review Board of Health Canada.

\section{RESULTS}

A total of 7823 completed questionnaires ( $n=5857$ English, $n=1966$ French) were received, yielding an overall response rate of $72 \%$. The respondents included individuals from all 10 Canadian provinces and two of the three territories (Northwest Territories and Yukon). There was approximately equal representation from metropolitan, urban and rural areas.

\section{General characteristics of respondents}

Of the 7823 respondents, 5912 (75\%) reported having had a biopsyconfirmed diagnosis of $\mathrm{CD}$ or dermatitis herpetiformis. Of these, 5092 had CD, 51 had dermatitis herpetiformis and 769 had both disorders, with one or both confirmed by biopsy. The results reported here are on these 5912 respondents.
The mean $( \pm$ SD) age of respondents was $56.4 \pm 15.2$ years (range 18 to 93 years). There was an approximate 3:1 female to male ratio ( $76 \%$ versus $24 \%$ ). Mean age at diagnosis was $45.4 \pm 16.4$ years (median 46.0 years); $5.4 \%$ were diagnosed before 18 years of age. Among those who reported their year of diagnosis, $34.7 \%$ were diagnosed before 1998, 18.3\% between 1998 and 2002 and 47\% between 2003 and 2008. Overall, $41.9 \%$ of respondents reported undergoing serological (antibody) testing in addition to biopsy.

\section{Duration of symptoms before diagnosis}

The mean duration of symptoms before diagnosis was $12.0 \pm 14.4$ years (median 5.5 years): among women, it was $12.6 \pm 14.4$ years (median seven years), and among men $10.3 \pm 14.1$ years (median four years). The duration of symptoms before diagnosis across three time periods (before 1998; 1998 to 2002; 2003 to 2008) averaged 12.5, 13.1 and 11.2 years, respectively.

\section{Clinical symptoms and recovery after GF diet}

Overall, $0.7 \%(n=43)$ of respondents reported no symptoms before diagnosis; $0.6 \%(n=38)$ reported anemia as their only symptom.

Symptoms reported before diagnosis are summarized in Table 1. Abdominal pain and bloating $(84.9 \%)$, extreme weakness/tiredness $(74.2 \%)$, diarrhea $(71.7 \%)$, anemia $(67.8 \%)$ and weight loss $(63.5 \%)$ were the most common symptoms. Of the 19 symptoms inquired, 17 were experienced by a significantly larger percentage of women than men; the exceptions were diarrhea and weight loss, which were reported approximately equally by both. Full recovery from symptoms ranged from a high of $89.9 \%$ for weight loss to a low of $34.0 \%$ for easy bruising. At the time of the survey, a significantly smaller percentage of women than men reported full recovery from abdominal pain/bloating, weakness, diarrhea, anemia, muscle cramps, constipation, migraine and edema of the hands and feet. There were no symptoms for which a higher percentage of women reported full recovery compared with men.

Among respondents, 59.5\% had been adhering to a GF diet for $>5$ years, $32.4 \%$ for one to five years and $8.1 \%$ for $<1$ year. The length of time on a GF diet was positively associated with symptom recovery. For 12 of the 19 symptoms queried, the percentage of respondents reporting full recovery was significantly higher among those who had been adhering to a GF diet for a longer time, with significant differences between those being on the GF diet for $<1$ year and those $>5$ years (Table 1$)$.

\section{Quality of life}

Regarding quality of life, $55.7 \%$ of respondents indicated it to be excellent or very good, with a significantly smaller percentage reported by women $(54.4 \%)$ versus men $(60.0 \%)$. Statistically significant differences were also observed across length of time on a GF diet. Of the respondents who had been following a GF diet $<1$ year, overall, $47.8 \%$ rated their quality of life as excellent or very good compared with $57.2 \%$ of respondents who had been adhering to a GF diet for $>5$ years.

\section{Symptoms experienced if something containing gluten was consumed while on a GF diet}

The majority of respondents (80\%) reported experiencing symptoms after ingesting something that contained gluten. The three most common symptoms included abdominal pain, bloating/gas and diarrhea (Table 2). Median time between ingestion and onset of symptoms was $2 \mathrm{~h}$ (mean $6.4 \mathrm{~h}$ ) with symptoms lasting a median of $24 \mathrm{~h}$ (mean $39.3 \mathrm{~h}$ ). Nine of the 11 symptoms queried were reported by a significantly higher percentage of women than men, the exceptions being diarrhea and itchy skin, which were reported approximately equally by both.

\section{DISCUSSION}

To our knowledge, the present study is the largest survey of its kind ever conducted among the celiac population investigating clinical symptoms and recovery while on a GF diet. The present study was 
TABLE 1

Symptoms and conditions experienced by respondents before diagnosis of celiac disease and while adhering to a gluten-free diet (GFD) ( $n=5698$ to 5775 )

\begin{tabular}{|c|c|c|c|c|c|}
\hline \multirow[b]{3}{*}{ Symptoms } & \multirow{3}{*}{$\begin{array}{c}\text { Experienced } \\
\text { before GFD }\end{array}$} & \multirow{2}{*}{\multicolumn{4}{|c|}{$\begin{array}{l}\text { Respondents who experienced symp- } \\
\text { toms before GFD who fully recovered } \\
\text { GFD, years }\end{array}$}} \\
\hline & & & & & \\
\hline & & Overall & $<1$ & $1-5$ & $>5$ \\
\hline $\begin{array}{l}\text { Abdominal pain/ } \\
\text { bloating }\end{array}$ & $84.9^{*}$ & $62.9^{\dagger}$ & 60.1 & 59.6 & $65.1^{\ddagger}$ \\
\hline $\begin{array}{l}\text { Extreme weak- } \\
\text { ness/tiredness }\end{array}$ & $74.2^{*}$ & $65.7^{\dagger}$ & 42.0 & 59.2 & $72.4^{\ddagger}$ \\
\hline Diarrhea & 71.7 & $75.3^{\dagger}$ & 67.3 & 70.7 & $78.3^{\ddagger}$ \\
\hline Anemia & $67.8^{*}$ & $80.1^{\dagger}$ & 55.2 & 77.9 & $83.5^{\ddagger}$ \\
\hline Weight loss & 63.5 & 89.9 & 72.7 & 86.6 & $92.7^{\ddagger}$ \\
\hline Irritability & $55.7^{\star}$ & 58.9 & 48.1 & 53.5 & $63.5^{\ddagger}$ \\
\hline Foul stools & $54.4^{\star}$ & 79.1 & 69.1 & 75.1 & $81.8^{\ddagger}$ \\
\hline Feeling depressed & $47.3^{*}$ & 55.7 & 45.4 & 52.3 & $59.4^{\ddagger}$ \\
\hline Mood swings & $45.1^{\star}$ & 52.8 & 46.8 & 49.4 & $55.9^{\ddagger}$ \\
\hline Bone/joint pain & $44.2^{*}$ & 35.5 & 31.4 & 33.9 & 37.2 \\
\hline Itchy skin & 40.3 & 39.4 & 26.2 & 40.5 & $40.8^{\ddagger}$ \\
\hline Easy bruising & $38.1^{*}$ & 34.0 & 31.7 & 34.6 & 34.1 \\
\hline Muscle cramps & $37.9 *$ & $49.7^{\dagger}$ & 47.6 & 49.6 & 50.2 \\
\hline Constipation & $36.5^{\star}$ & $52.3^{\dagger}$ & 43.3 & 51.5 & 54.2 \\
\hline Oral ulcers & $30.9^{*}$ & 66.9 & 59.8 & 65.4 & 68.7 \\
\hline Lactose intolerance & $28.9 *$ & 42.9 & 37.7 & 41.5 & 44.4 \\
\hline Migraine & $28.6^{*}$ & 52.5 & 41.8 & 52.2 & 54.1 \\
\hline Nausea/vomiting & $26.9^{*}$ & 81.7 & 70.1 & 76.7 & $85.7^{\ddagger}$ \\
\hline
\end{tabular}

Data presented as \%. *Significantly more women than men experienced the symptom before starting a GFD ( $P<0.01)$; 'Significantly more men than women had fully recovered from the symptom at the time the survey was conducted $(P<0.01) ;{ }^{\ddagger}$ Significant differences in the percentages of respondents who had fully recovered from the symptom across the three categories of length of time adhering to a gluten-free diet $(P<0.01)$

conducted to help better define and understand the current state of $\mathrm{CD}$ in Canadian adults and to compare the results with those of the Canadian Celiac Health Survey performed in 2002 (20).

General characteristics of respondents:

The number of respondents with a biopsy-proven diagnosis of CD or dermatitis herpetiformis in the present survey was $80 \%$, which is slightly lower than the $86 \%$ reported in the previous Canadian study (20), and higher than the $75 \%$ reported in a United States national survey (28). These variations in the percentage of individuals reporting having small intestinal biopsy performed may be due, in part, to the differences in the populations surveyed. Another possible explanation is that as serological tests have become more readily available, some patients may have been diagnosed with $\mathrm{CD}$ based on an abnormal serological test without a biopsy.

The female:male ratio of 3:1 observed in the present survey is a common finding in studies involving adults with symptomatic CD $(28,29)$. Although population-based studies $(1,30)$ show more balanced distribution between females and males, a study with sibling design supports the view that being female is associated with an increased risk of $\mathrm{CD}$ in childhood (31). Reasons for this sex difference remain unknown. However, sex differences of disease occurrence have also been observed for other autoimmune diseases including type I diabetes and hypothyroidism $(22,32,33)$. The higher frequency occurrence of these conditions among women is believed to be attributable, at least in part, to the influence of sex hormones and genetics $(33,34)$.

Delays in diagnosis of CD

The mean age at diagnosis of 45.4 years and a mean duration of symptoms before diagnosis of 12.0 years in the present study was comparable
TABLE 2

Type of reaction experienced with gluten exposure while adhering to a gluten-free diet (GFD) ( $n=4613$ to 4728 )

\begin{tabular}{lcccccc}
\hline & & & & \multicolumn{3}{c}{ GFD, years } \\
\cline { 5 - 7 } Reaction & Overall & Men & Women & $<1$ & $\mathbf{1 - 5}$ & $>\mathbf{5}$ \\
\hline Abdominal pain & 79.0 & 71.8 & $81.1^{*}$ & 76.2 & 78.9 & 79.3 \\
Bloating/gas & 74.4 & 66.0 & $77.0^{*}$ & 76.8 & 74.6 & 74.0 \\
Diarrhea & 71.6 & 72.1 & 71.2 & 68.7 & 66.8 & $74.4^{\dagger}$ \\
Tiredness & 44.1 & 36.7 & $46.5^{*}$ & 45.5 & 41.8 & 45.1 \\
Weakness & 28.3 & 25.3 & $29.4^{*}$ & 28.0 & 26.8 & 29.1 \\
Nausea/vomiting & 26.7 & 17.7 & $29.3^{*}$ & 21.1 & 25.2 & $28.1^{\dagger}$ \\
Itchy skin & 21.9 & 24.2 & 21.4 & 24.1 & 23.5 & 20.8 \\
Constipation & 17.1 & 10.4 & $19.1^{*}$ & 15.7 & 19.5 & 16.1 \\
Feeling & 17.0 & 14.2 & $17.7^{*}$ & 19.9 & 16.3 & 17.0 \\
$\quad$ depressed & & & & & & \\
Migraine & 13.9 & 7.6 & $15.8^{*}$ & 15.1 & 14.9 & 13.1 \\
$\quad$ headache & & & & & & \\
Oral ulcers & 9.7 & 6.2 & $10.8^{*}$ & 9.0 & 9.1 & 10.1 \\
\hline
\end{tabular}

Data presented as \%. *Significant differences between men and women $(P<0.01) ;{ }^{\dagger}$ Significant differences across the three categories of time on GFD $(P<0.01)$

with the previous Canadian study (20) conducted in 2002 (mean age of 46 years at diagnosis; mean delay in diagnosis of 11.7 years). These findings are also comparable with surveys of individuals with CD in the United States and the United Kingdom. In the United States, the mean age at diagnosis was noted to be 45 years and mean delay in diagnosis 11 years (28); in the United Kingdom, mean age at diagnosis was 41.3 years and mean delay in diagnosis was 13.2 years $(35)$. These findings confirm that awareness of CD needs to be improved both in North America and abroad.

Consistent with the improved availability of serological tests in clinical practice, we found a significant increase in the number of respondents undergoing serological testing in addition to biopsy, increasing from $20 \%$ in the late 1990 s to more than $60 \%$ between 2003 and 2008. Unfortunately, the increased use of serological testing was not associated with a decrease in the time to diagnosis. In the present study, the delay in diagnosis of $\mathrm{CD}$ varied little over time. Among those diagnosed before 1998, from 1998 to 2002, and 2003 to 2008, the delay in diagnosis averaged 12.5 years, 13.1 years and 11.2 years, respectively. Similar results were reported from the United Kingdom (35), where a mean delay in diagnosis of 14.5 years was found among individuals diagnosed with CD before 2000 and 12.0 years among those diagnosed after 2000. The reasons for these results are not clear. CD can present with minimal or nongastrointestinal symptoms and, thus, may escape recognition by the primary care physician. This was also observed in the previous Canadian study in which a significant number of patients, both children and adults with CD, were assessed by a number of family physicians, pediatricians/internists and even gastroenterologists before the diagnosis was made $(10,20)$. There is a need to improve primary care physicians' awareness of the diverse clinical presentation of CD. A large multicentre study involving primary care physicians demonstrated that increased use of serological screening can lead to significantly improved rate of diagnosis of CD (36). An early diagnosis and treatment will not only prevent morbidity for patients with CD but will also have an economic advantage by reducing the medical costs of care (37).

Clinical features at diagnosis

The most frequently reported symptoms (abdominal pain, extreme weakness, diarrhea and weight loss) before diagnosis of CD in the present study were similar to those reported in the previous Canadian survey (20). Similar findings were reported in the survey from the United Kingdom (35). All of these symptoms are well described and can be considered classical symptoms of CD $(16,38)$. The pattern of 
major symptoms does not appear to have changed over time. However, it is possible that some or many of the respondents in the present study had also participated in the previous survey. Less frequently, but consistent with the previous Canadian (20) and other studies, a variety of nonclassical symptoms, such as fatigue and anemia, were also commonly reported by respondents (Table 1).

\section{Symptom recovery on a GF diet}

Comparing the 14 symptoms reported in the two Canadian surveys on $\mathrm{CD}$, full recovery was reported by a slightly higher percentage of respondents in the present survey compared with the previous one (20) including: weight loss (90\% versus $84 \%$ ), abdominal pain/bloating (63\% versus $52 \%)$ and anemia $(80.1 \%$ versus $72 \%)$. The difference is small and may reflect different population characteristic or better access to information on CD and the GF diet. Annibale et al (39) reported $94.4 \%$ of patients with iron deficiency anemia recovered after a year on a GF diet alone, correlating with normalization of intestinal mucosa.

\section{Recovery versus length of time on GF diet}

In the present survey, the percentage of respondents reporting full recovery from symptoms was significantly higher among respondents who had been adhering to a GF diet for $>5$ years. Nonetheless, a substantial proportion of these respondents ( $7 \%$ to $63 \%$ depending on the specific symptom) had not experienced full recovery. In a recent study from the United States (14), mucosal recovery was reported in only $66 \%$ of adults with CD after being in treatment with GF diet for five years.

Some patients with CD can remain symptomatic despite being on a GF diet, a phenomenon referred to as nonresponsive CD $(40,41)$. All respondents in the present study had biopsy-confirmed CD; therefore, a misdiagnosis is unlikely. There could be several other reasons for this lack of full recovery including poor compliance, dietary crosscontamination with gluten, postinflammatory irritable bowel syndrome and development of other complications such as small bowel bacterial overgrowth, pancreatic insufficiency and refractory CD. The study design did not enable us to differentiate these various causes. However, the number of patients continuing to experience the original symptom - even after five years on a GF diet - is significant. Dietary gluten exceeding $10 \mathrm{mg}$ per day has been shown to cause small intestinal mucosal injury in sensitive individuals (42). One wonders whether, despite best attempts, many of these patients may be inadvertently consuming a diet that is contaminated with gluten. Better education of patients, food manufacturers and the food service industry, along with improved labelling of food products, beverages and medications, could all help reduce the risk of inadvertent gluten exposure in those needing a strict GF diet. It is hoped that the recently introduced labelling laws for gluten in prepackaged foods in Canada will help improve this situation.

It is recommended that patients with $\mathrm{CD}$ be managed using a multidisciplinary approach including a gastroenterologist, dietitian and family physician $(43,44)$. On diagnosis, patients should be referred to a registered dietitian skilled in the GF diet to receive proper nutritional counselling. Patients also benefit from the help of a celiac support group $(9,45)$. Strict adherence to a GF diet and regular medical and dietetic follow-up will reduce the risk of long-term complications.

\section{Sex differences on symptom presentation, recovery and quality of life}

Sex differences in clinical presentation of CD have been reported by others (46). In our study, except for diarrhea and weight loss, all presenting symptoms queried were reported by a significantly higher percentage of women than men. Anemia was the fourth most common clinical presentation reported by $68 \%$ of respondents, with $38(0.6 \%)$ respondents reporting anemia as their only presenting symptom. Extreme weakness, the second most common presenting symptom, may be due, in part, to anemia. These findings are consistent with other studies reporting a high prevalence of anemia before diagnosis of $\mathrm{CD}$, and support the recommendation that individuals, particularly women, with anemia that is unresponsive to treatment, should be investigated for CD $(17,36,47)$.

Sex differences were also apparent in symptom recovery and quality of life. A significantly smaller percentage of women reported full recovery from symptoms compared with men (Table 1). Continuing symptoms experienced by women in the present study may at least partially explain why their reported quality of life was also lower than men. Similar perception of quality of life has been reported by others (48). Although a modified survey instrument was used in the present survey compared with the previous survey (20), both found that respondents who were on a GF diet for $<1$ year reported a significantly lower quality of life.

\section{Short-term response to gluten ingestion while on a GF diet}

In the present study, the majority of patients (80\%) with CD reported symptoms after ingesting something containing gluten while on GF diet (Table 2). The median time to symptoms was $2 \mathrm{~h}$, and the median duration $24 \mathrm{~h}$. The most common symptoms experienced included abdominal pain, bloating/gas, diarrhea and vomiting. The possible mechanisms of short-term symptoms after gluten ingestion may include abnormalities in intestinal permeability and triggering of neural pathways $(32,49)$.

It is important to recognize that not all patients with CD experience symptoms after accidental gluten ingestion. Experiencing symptoms after gluten ingestion may, in a way, be helpful to the patient in recognizing the gluten exposure and averting such events in the future. However, for those with CD who do not experience such symptoms after gluten ingestion, there could be a risk of ongoing small intestinal mucosal injury and its associated complications. These individuals should be made very aware of the possible repercussions of consuming even small amounts of gluten.

There are limitations to the present study that need to be recognized. As in any survey, not all respondents answer every question, resulting in some incomplete data sets. Participant responses may also have been subject to recall bias due to the long time interval covered. Furthermore, because there is no CD patient registry in Canada, it was not possible to study a random sample. All members of the two national celiac support groups (CCA and FQMC) were surveyed. Because not all patients with CD become members of a support group, the study may not be representative of all Canadians with this disorder. However, the number of subjects studied was quite large (almost 6000), representing all 10 Canadian provinces with approximately equal representation from metropolitan, urban and rural areas, thus providing a broad population sample. To keep the study population well defined, only biopsy-proven patients were included in the data analysis and, conceivably, some with true CD whose diagnosis was based solely on symptoms and a positive serological test may have been excluded.

\section{CONCLUSIONS}

Delays in diagnosis of CD in Canada remain long despite increased availability of serological testing. A substantial number of adult patients continue to experience symptoms even after adhering to a GF diet for $>5$ years, with women experiencing significantly more symptoms and a lower recovery rate than men. Effective strategies for both the public and the medical profession, especially family physicians and dietitians, need to be developed for timely diagnosis, appropriate management and follow-up of patients with CD.

ACKNOWLEDGEMENTS: The authors thank the members of the Canadian Celiac Association (CCA) and the Fondation québécoise de la maladie coeliaque for their enthusiastic participation in the survey. The authors are also thankful to the CCA Professional Advisory Board members for their contribution to the survey; $\mathrm{M}$ Prince for data entry and analysis; C Stich and B Knäuper for their psychometric expertise during the preparation of the questionnaire; and Michael Abbott and Frank Geraghty for reviewing the manuscript. 
SUPPORT: This study was supported by funds from the Bureau of Chemical Safety, Health Canada and the J Alexander Campbell Research Fund of the Canadian Celiac Association.

DISCLOSURES: The authors have no financial disclosures or conflicts of interest to declare.

\section{REFERENCES}

1. Fasano A, Berti I, Gerarduzzi T, et al. Prevalence of celiac disease in at-risk and not-at-risk groups in the United States: A large multicenter study. Arch Intern Med 2003;163:286-92.

2. Sapone A, Bai JC, Ciacci C, et al. Spectrum of gluten-related disorders: Consensus on new nomenclature and classification. BMC Med 2012;10:13.

3. Ludvigsson JF, Leffler DA, Bai JC, et al. The Oslo definitions for coeliac disease and related terms. Gut 2013;62:43-52.

4. American Gastroenterological Association (AGA) Institute medical position statement on the diagnosis and management of celiac disease. Gastroenterology 2006;131:1977-80.

5. Leffler DA, Schuppan D. Update on serological testing in celiac disease. Am J Gastroenterol 2010;105:2520-4.

6. Murray JA, Van Dyke C, Plevak MF, et al. Trends in the identification and clinical features of celiac disease in a North American community, 1950-2001. Clin Gastroenterol Hepatol 2003;1:19-27.

7. Zarkadas M, Case S. Celiac disease and the gluten-free diet an overview. Topin Clin Nutr 2005;20:127-38.

8. Rashtak S, Murray JA. Coeliac disease: New approaches to therapy. Aliment Pharmacol Ther 2012;35:768-81.

9. Zarkadas M, Cranney A, Case S, et al. The impact of a gluten-free diet on adults with coeliac disease: Results of a national survey. J Hum Nutr Diet 2006;19:41-9.

10. Rashid M, Cranney A, Zarkadas M, et al. Celiac disease: Evaluation of the diagnosis and dietary compliance in Canadian children. Pediatrics 2005;116:e754-e759.

11. Sverker A, Hensing G, Hallert C. "Controlled by food" - lived experiences of coeliac disease. J Hum Nutr Diet 2005;18:171-80.

12. Whitaker JK, West J, Holmes GK, Logan RF. Patient perceptions of the burden of coeliac disease and its treatment in the UK. Aliment Pharmacol Ther 2009;29:1131-6.

13. Leffler DA, Edwards-George J, Dennis M, et al. Factors that influence adherence to a gluten-free diet in adults with celiac disease. Dig Dis Sci 2008;53:1573-81.

14. Rubio-Tapia A, Rahim MW, See JA, Lahr BD, Wu TT, Murray JA. Mucosal recovery and mortality in adults with celiac disease after treatment with a gluten-free diet. Am J Gastroenterol 2010;105:1412-20.

15. Fasano A. Clinical presentation of celiac disease in the pediatric population. Gastroenterology 2005;128(4 Suppl 1):S68-S73.

16. Rubio-Tapia A, Murray JA. Celiac disease. Curr Opin Gastroenterol 2010;2:116-22.

17. Harper JW, Holleran SF, Ramakrishnan R, Bhagat G, Green PH. Anemia in celiac disease is multifactorial in etiology. Am J Hematol 2007;82:996-1000.

18. Jackson JR, Eaton WW, Cascella NG, Fasano A, Kelly DL. Neurologic and psychiatric manifestations of celiac disease and gluten sensitivity. Psychiatr Q 2012;83:91-102.

19. Kostopoulou O, Devereaux-Walsh C, Delaney BC. Missing celiac disease in family medicine: The importance of hypothesis generation. Med Decis Making 2009;29:282-90.

20. Cranney A, Zarkadas M, Graham ID, et al. The Canadian Celiac Health Survey. Dig Dis Sci 2007;52:1087-95.

21. Fasano A. Systemic autoimmune disorders in celiac disease. Curr Opin Gastroenterol 2006;22:674-9.

22. Armstrong MJ, Hegade VS, Robins G. Advances in coeliac disease. Curr Opin Gastroenterol 2012;2:104-12.

23. West J. Celiac disease and its complications: A time traveller's perspective. Gastroenterology 2009;136:32-4.

24. Tio M, Cox MR, Eslick GD. Meta-analysis: Coeliac disease and the risk of all-cause mortality, any malignancy and lymphoid malignancy. Aliment Pharmacol Ther 2012;35:540-51.
25. Leslie LA, Lebwohl B, Neugut AI, et al. Incidence of lymphoproliferative disorders in patients with celiac disease. Am J Hematol 2012:87:754-59.

26. Grainge MJ, West J, Card TR, Holmes GKT. Causes of death in people with celiac disease spanning the pre- and post-serology era: A population-based cohort study from Derby, UK. Am J Gastroenterol 2011;106: 933-39.

27. Zarkadas M, Dubois S, Collins K, et al. Living with celiac disease and a gluten-free diet: A Canadian perspective. J Hum Nutr Diet 2013;26:10-23.

28. Green PH, Stavropoulos SN, Panagi SG, et al. Characteristics of adult celiac disease in the USA: Results of a national survey. Am J Gastroenterol 2001;96:126-31.

29. Hauser W, Stallmach A, Caspary WF, Stein J. Predictors of reduced health-related quality of life in adults with coeliac disease. Aliment Pharmacol Ther 2007;25:569-78.

30. Reilly NR, Green PHR. Epidemiology and clinical presentations of celiac disease. Semin Immunopathol. 2012;34:473-78.

31. Wingren CJ, Agardh D, Merlo J. Sex differences in coeliac disease risk: A Swedish sibling design study. Dig Liver Dis 2012;44:909-13.

32. Fasano A. Leaky gut and autoimmune diseases. Clin Rev Allergy Immunol 2012;42:71-8.

33. Amur S, Parekh A, Mummaneni P. Sex differences and genomics in autoimmune diseases. J Autoimmun 2012;38:J254-J265.

34. Nussinovitch U, Shoenfeld Y. The role of gender and organ specific autoimmunity. Autoimmun Rev 2012;11:A377-A385.

35. Gray AM, Papanicolas IN. Impact of symptoms on quality of life before and after diagnosis of coeliac disease: Results from a UK population survey. BMC Health Serv Res 2010;10:105-12.

36. Catassi C, Kryszak D, Louis-Jaques O, et al. Detection of celiac disease in primary care: A multicenter case-finding study in North America. Am J Gastroenterol 2007;102:1454-60.

37. Long KH, Rubio-Tapia A, Wagie AE et al. The economics of coeliac disease: A population-based study. Aliment Pharmacol Ther 2010;32:261-9.

38. Catassi C, Fasano A. It is really celiac disease? Pitfalls of diagnosis. Curr Gastroenterol Reports 2008;10:466-72.

39. Annibale B, Severi C, Chistolini A, et al. Efficacy of gluten-free diet alone on recovery from iron deficiency anemia in adult celiac patients. Am J Gastroenterol. 2001;9:132-7.

40. Leffler DA, Dennis M, Hyett B, Kelly E, Schuppan D, Kelly CP. Etiologies and predictors of diagnosis in nonresponsive celiac disease. Clin Gastroenterol Hepatol 2007;5:445-50.

41. Dewar DH, Donnelly SC, McLaughlin SD, Johnson MW, Ellis HJ, Ciclitira PJ. Celiac disease: Management of persistent symptoms in patients on a gluten-free diet. World J Gastroenterol 2012;28;18:1348-56.

42. Catassi C, Fabiani E, Iacono G, et al. A prospective, double-blind, placebo-controlled trial to establish a safe gluten threshold for patients with celiac disease. Am J Clin Nutr 2007;85:160-6.

43. Kagnoff MF. AGA institute medical position statement on the diagnosis and management of celiac disease. Gastroenterology 2006;131:1977-80.

44. Pietzak MM. Follow-up of patients with celiac disease: Achieving compliance with treatment. Gastroenterology 2005;128:S135-S141.

45. Jacobsson LR, Friedrichsen M, Goransson A, Hallert C. Impact of an active patient education program on gastrointestinal symptoms in women with celiac disease following a gluten-free diet: A randomized controlled trial. Gastroenterol Nurs 2012;35:200-6.

46. Bardella MT, Fredella C, Saladino V, et al. Gluten intolerance: Gender- and age-related differences in symptoms. Scand J Gastroenterol 2005;40:15-9.

47. Jones R, Sleet S. Easily missed? Coeliac disease. BMJ 2009;338:a3058.

48. Hallert C, Sandlund O, Broqvist M. Perceptions of health-related quality of life of men and women living with celiac disease. Scand J Caring Sci 2003;17:301-7.

49. Cady RK, Farmer K, Dexter JK, Hall J. The bowel and migraine: Update on celiac disease and irritable bowel syndrome. Curr Pain Headache Rep 2012;16:278-86. 


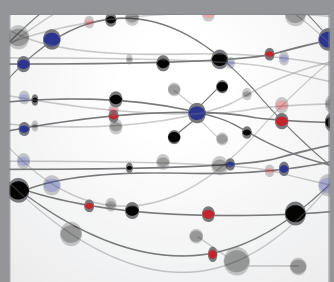

The Scientific World Journal
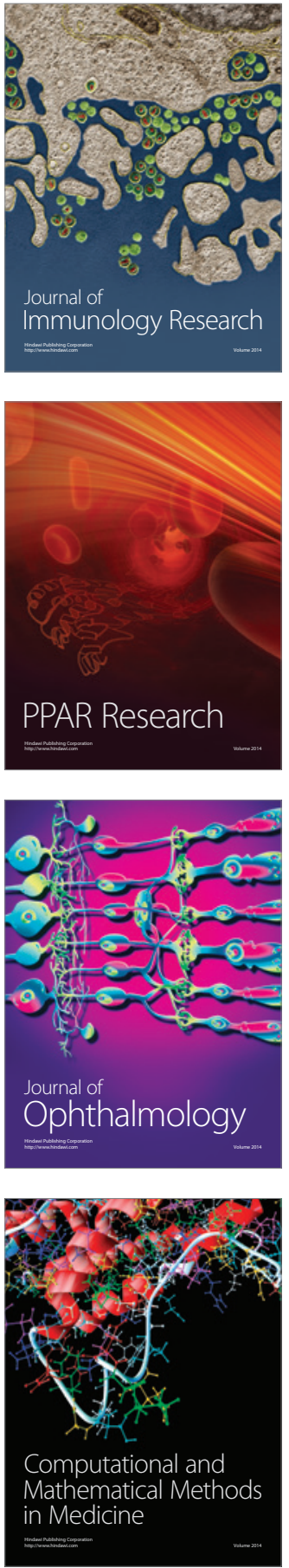

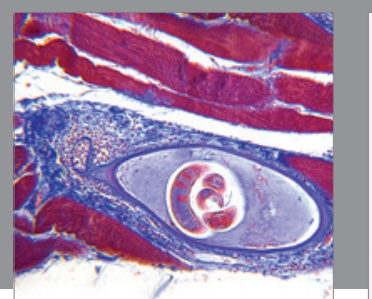

Gastroenterology Research and Practice

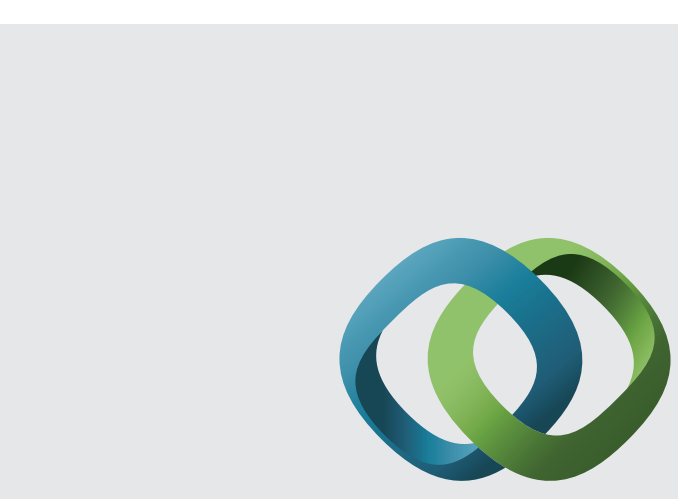

\section{Hindawi}

Submit your manuscripts at

http://www.hindawi.com
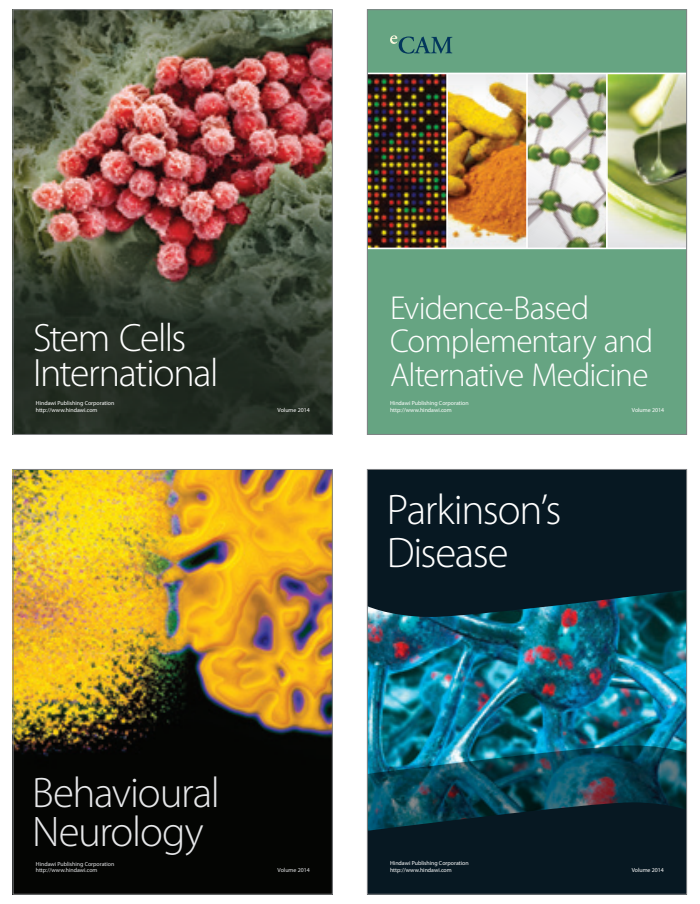
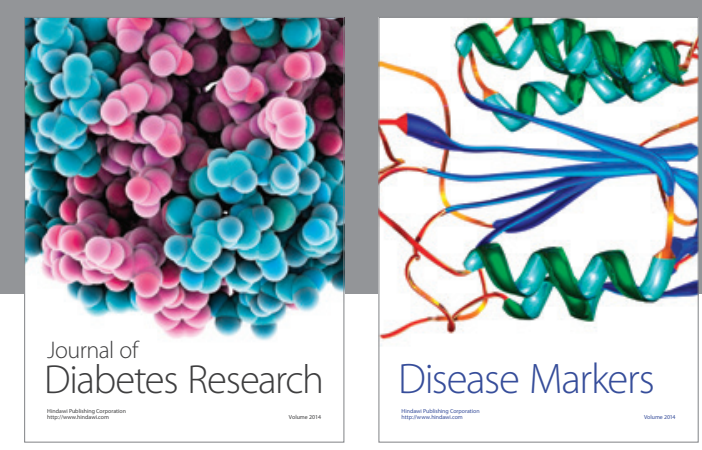

Disease Markers
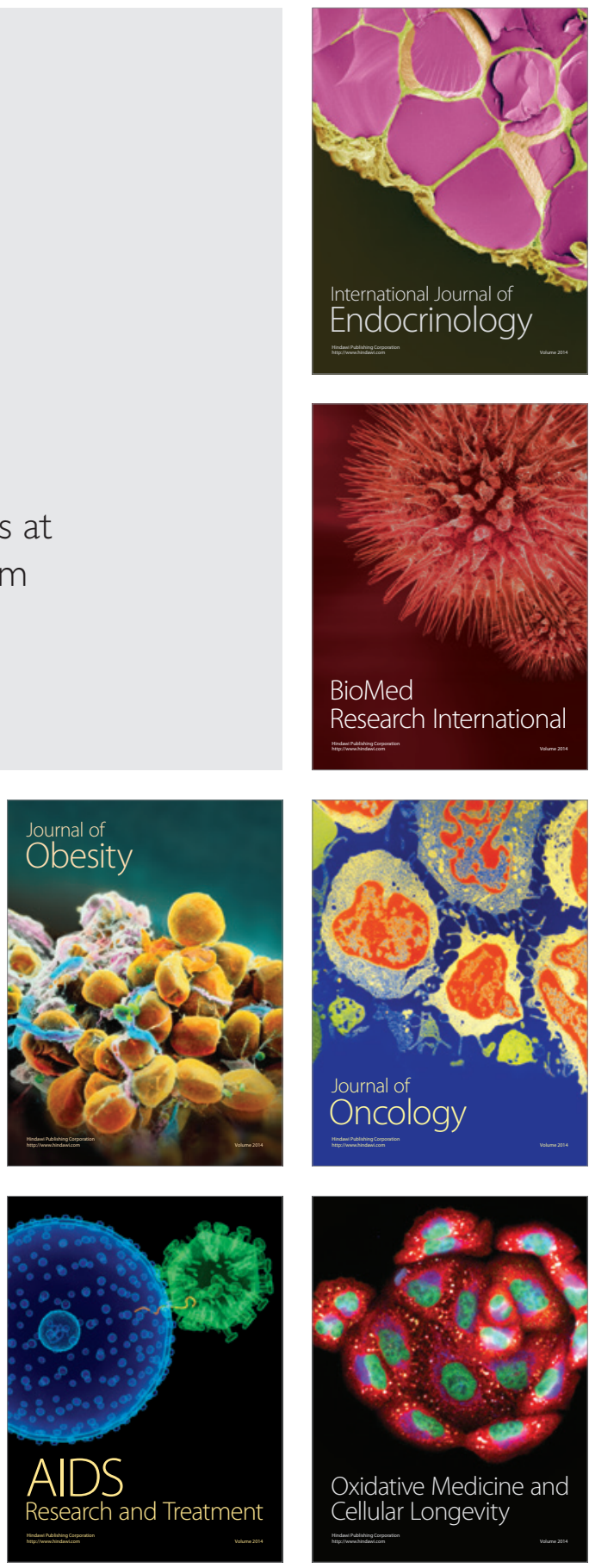